\title{
Diabetes Therapy Podcast: ATTD Conference Highlights
}

Sufyan Hussain · Tim Street

Received: June 10, 2020 / Published online: July 25, 2020

(C) The Author(s)

VG: Hello and welcome to the Diabetes Therapy podcast. Today we are speaking to Dr. Sufyan Hussain, consultant physician in diabetes and endocrinology and honorary senior clinical lecturer at Guy's and St Thomas' NHS Foundation Trust and Kings College London. Today Sufyan will be speaking with Tim Street who is the director of Diabettech.

SH: Thank you for joining us, Tim. I know it is a busy time. I note that you are in the Financial Times today actually commenting on lots of diabetes technology related things. Tim Street as mentioned is the director of Diabettech and I am sure he will tell us a bit more about this. I personally came across Tim many years back actually at a meeting related to type 1

Digital Features To view digital features for this article go to https://doi.org/10.6084/m9.figshare.12459692.

Electronic Supplementary Material The online version of this article (https://doi.org/10.1007/s13300020-00862-6) contains supplementary material, which is available to authorized users.

S. Hussain

Guy's and St Thomas' NHS Foundation Trust,

London, UK

S. Hussain $(\bowtie)$

King's College London, London, UK

e-mail: Sufyan.hussain@kcl.ac.uk

T. Street

Diabettech, London, UK

e-mail: tim@diabettech.com diabetes and I remember Tim sticking his hand up and being the first person I came across using an artificial pancreas system [APS]. This was my introduction to Tim and over the years I have got to know him more and we're doing a lot of work on similar themes and we have spent some time recently at the ATTD [Advanced Technologies \& Treatments for Diabetes] conference which was great, and hence we have him here to tell us about the highlights of the ATTD conference. So, a bit about Tim. He is obviously the director of Diabettech, which he will tell you about, but in addition to this, he does a lot of advocative work in relation to diabetes technology. He is an excellent advocate for type 1 diabetes technology; he is a person with diabetes and was an engineer in a former life. He is well regarded as one of the leading authorities for the 'Do it yourself' artificial pancreas systems as well so lots of boxes to tick. So, Tim, how are you?

TS: I am good thank you, Sufyan.

SH: Let's start with a little bit about yourself. You are doing a lot of great work with your website. Would you like to tell the listeners about what you're doing?

TS: Yes, I write diabettech.com which is a website that is about diabetes technology and treatments and looks at upcoming treatments and upcoming technologies and also a lot in the 'DIY' space. I try to undertake any observational studies on myself looking at various aspects of 
living with the technologies and diabetes and try to figure out how people can better use the technologies that are available. I have done quite a few bits of experimentation where I have looked at the performance of various CGM [continuous glucose monitoring] systems and how they compare in real-world use on an $N=1$ basis, which some people have found useful in terms of deciding what it is they want to do relating to choosing CGM systems as well as looking at some of the data you can get off the DIY artificial pancreas systems and figuring out how that can be used to change the way we look at how type 1 diabetes operates over a period of time.

SH: Wow excellent. You know Professor Lawrence actually did a lot of experimentation on himself when they came out with new insulins in that era. You're following very similar footsteps to a great legend aren't you, Tim?

TS: I like to think so!

SH: We will talk a little about your work and your poster as well towards the end. Would you like to tell the viewers a little bit about yourself, as a person, and what you do and your background and how you got to do what you're doing?

TS: Yes, I have had type 1 since I was 13 which is now getting on for some 31 years. I grew up going through my senior school years and then university as a person living with type 1 . I started on the two times a day insulin regimen where you ate to the insulin and then progressed onto the early MDI [multiple daily injections] before moving onto the more advanced insulin a bit later on. I eventually moved through onto the more modern treatments relating to pumps and found my way onto DIY systems after attending the GBDOC conference in I think 2016 back in Nottingham, which was an enlightening experience, meeting people such as Tim Omer who in the UK has been in the forefront of some of that work. But, type 1 diabetes is not the only thing that I am and the thing I think about. I have played cricket for 30 years, travelling to Jamaica to play as a touring team. I have travelled the world, I have four dogs that are accompanying me as I do this podcast and I have a very full life outside of living with diabetes and doing DIY stuff. I have had two different careers, one in a technology engineering world and another working in finance. So, whilst the stuff I do relating to DIY systems is obviously important to me and I gain benefit from it so it is not the only thing I do with my time.

SH: So now, moving on to Advanced Technologies and Treatment for Diabetes conference that was held in Madrid just a few weeks back between the 19th and 22nd of February. We will go through some themes and discuss your highlights. For me, the biggest highlight was meeting people, networking, getting to know and discuss what they are up to. Do you agree with that, Tim?

TS: You're right. I think it's a fantastic opportunity to meet people from the medical world and people with diabetes all arriving at the same place and wanting to talk to each other. Another thing that was great was that I discovered there was the pretty open dialogue with many of the companies that provide the technology to us that were willing to have a conversation and to listen to some of the concerns that we have.

$\mathrm{SH}$ : That is true. I think it was a great place for academics, healthcare professionals, people with diabetes and industry to come together. Initially thinking about insulins, Tim, do you have thoughts on any updates that came from ATTD on new insulins or new therapies?

TS: As you will be aware, I have written quite a bit about URLi (ultra rapid lispro) as it gets called or Liumjev is the brand name that [Eli] Lilly has chosen for their ultra-rapid lispro which was well presented at EASD [European Association for the Study of Diabetes] last year. It looks like it's a new fast-track insulin that is faster than Fiasp (fast-acting insulin aspart) and according to the data presented at ATTD it appears to be less likely to cause site issues, which we know was an issue with Fiasp. So right now that looks like it is going to be the next really interesting insulin on the market. There were also a few presentations around other analogues that are available and they presented further the data relating to things like safety and reduction in hypos etc., but for me, URLi is the one that stands out that is the next really interesting thing. Especially when they 
presented the graph that showed they had given people without diabetes and people with diabetes the same meal and the glucose excursions they saw in the $2 \mathrm{~h}$ post prandially in the people they had given URLi to were lower than the people without diabetes. I thought that was absolutely fascinating and presents a really interesting insulin to us to get our hands on. But of course, we now have to wait for that to go through the European Medical Association and get approval and then of course however long it takes in the UK to get it onto prescriptions for everybody to use.

SH: Indeed, it is one of the most exciting aspects and updates on insulin treatment at the conference and yes annoyingly there will be procedural steps that we will have to wait for before it will become available. But yes it's exciting and I think for those listening it's a reminder about why we need faster insulins and insulins that work quickly and wear off quickly, because given what we have now, not just with artificial pancreas systems but equally also with people on multiple daily insulin injections, the advantages of not having to give as prolonged a meal announcement or not having to plan things as far in advance which can be very practically challenging. And even knowing the insulin will wear out quicker if you're planning exercise or activities, you're not exposed to more insulin that could cause hypos. As you mentioned, Tim, it will also have an effect on the post-prandial glucose reductions and being much better at doing that by working much quicker.

TS: The other thing that stood out in terms of treatments was the debate and the ongoing debate relating to SGLT2 [sodium/glucose cotransporter 2] and the safety of that with people with type 1 diabetes. I think it's an interesting drug and I think the way it works and having spoken to people who have been put on it is also fascinating. At the same time, I understand there are concerns amongst professionals: the risk associated with euglycemic diabetic ketoacidosis (DKA) and whether that's going to be a bigger drain on resources offering this as a treatment. However, I think the debate highlighted that there is this concern and I think it's hard to come down on one side or the other until we have seen more use of it and more evidence one way or another. For me it is an interesting view that we are starting to look at multifactor approaches at dealing with type 1 that perhaps in the past we would be missing. That was also a good thing.

$\mathrm{SH}$ : It is a very important area in the management of type 1 diabetes. Looking at how we can manage it differently. At the moment in the clinical world we gain experience and we have had some good results in certain situations and you're right, risk of euglycemeic DKA is not something we can ignore and there has to be a little thought around education, using it in the correct circumstances and ongoing monitoring that will be needed. Obviously the worry is as you scale up and as you use it on more people the risk of events happening does increase. That is something we will be watching very closely. At the moment and in the last few months we have had approval for its clinical use so hopefully it will be gaining more clinical experience. But it was interesting to see the debates and discussions from various people being involved in the research at ATTD. Moving onto some other aspects like continuous glucose monitoring. Were there any things that you recall from the conference that stood out?

TS: I think that CGM had a lot of presence at the conference and it was very clear that there are new entrants who are trying to pick up market share from Dexcom who may not be offering what one might describe as 'an efficient a solution' that are trying to highlight their unique selling point on other things. So, for example, the more environmentally friendly approach that they take was one of the key selling points for one of the providers. We also hear about cost from some of them, and these are the guys that have apparently got medical approval for their devices and should be having them available to buy later this year. There are a plethora of them; many of them have a mean absolute relative difference (MARD) that is somewhere around the equivalent of the G4/ G5. Most of them require calibration but for me the stand out CGM is one that's still in a fairly early stage. It was the Metronom product and the reason this stood out so clearly was because it doesn't use the same technique as every other 
CGM on the market. It is a completely novel approach to measuring glucose levels and the way it works is it looks at the oxygen in the interstitial fluid rather than the output of the glucose oxidase hydrogen peroxide reaction. The reason it's really interesting is because at low levels of glucose in the interstitial fluid it is able to operate as efficiently as it is at high levels which means you don't need the same level of membranes overlaying the sensor and means in theory you have much better readings across the board. Their raw data output has a something that was somewhere between 9 and 9.5. That's raw data with no post processing and I think they are about to go into clinical trials in a phase 1 level. So what comes out at the end of this is going to be really interesting. The other thing that ties into that is their manufacturing process which is based off printing rather than the models that other centres use, meaning they can probably produce stuff at a lower cost. Whether it sells as that is another question. Another thing about their structure is that they have this fantastic model whereby they can have a four-part sensor and one of those parts can be used to check the quality of the site and whether the data that the other parts of the sensor being used for glucose levels is receiving works. So with that combination, you could in theory use that alongside things like cannulas to check quality of the cannula site. It has possibility of being used in multiple levels and that to me is really interesting. I think they are one to keep an eye on over the next couple of years as they go through clinical trials and potentially bring a product to market as I personally think it is something that is what is going to blow what is already there out of the water. It is a completely new product and approach to CGM that is superior to everything else that's out there.

SH: Exciting. I think you're right that there are lots of players in the CGM market and were hoping that in the years to come we will see more options available and opportunities as well to increase access if we can get our hands on CGM options that will be cheaper with longer wear and be accurate as well. It is a very interesting space. For me a bit that stuck out is not perhaps as technologically advanced but really thinking about education, education for people with diabetes and healthcare professionals to use the technology, particularly around CGM. That is a theme that has been present but we can hear that noise getting louder and louder and that realisation that we do need good education programmes, particularly for people with type 1 diabetes who are going to be using CGM. Going back and also thinking about how we did DAFNE (Dose Adjustment For Normal Eating), the education programme for type 1 diabetes with meters, having similar structured approaches to be able to offer the wider spectrum of type 1 diabetes that we see in our clinics, the education that they need that they can use the data from CGM, the arrows, also how they manage anxiety that can sometimes come from having a device with you giving you glucose readings all the time, understanding how to review the data. I think one of the talks was talking about thinking fast and thinking slow which tried to draw that comparison ensuring when you are in the moment, you are training yourself how to use the data to get through a situation but then obviously reflecting back and seeing trends and making the right adjustment to manage your type 1 diabetes better. There's some training and some work we need to do as healthcare professionals to be able to improve the actual use of these devices and equally there is also a lot of training needed for healthcare professionals as a whole. For me, this was a reminder and it was good to see that and see those messages come out in different shapes and forms.

TS: I think you're right, there is a part to play there that hasn't been well highlighted in all the discussions around technology. We saw some of that in presentations related to the use of technology and psychological factors within the conference because there was an entire session looking at what happens when people are diagnosed and how their psychological approach is impacted over the first 3 years of the diagnosis period and the support they get within that. It also looked at the instant effect and the long-term effects of having to live with the condition and what it does to your approach to life and I think that way a really good session that is worth people logging into 
the ATTD website and reviewing that on the video replays. I thought, as someone who was diagnosed a long time ago, it was really interesting and highlighted some important things for people who are diagnosed as adults.

$\mathrm{SH}$ : Indeed, psychological factors and aspects related to technology were a big theme and the bit you mentioned was indeed a very useful session that would be great for anyone to log in and view it. There were lots of related aspects to it in other forms as well that came about. Then moving onto pumps; is there anything in particular you recall as a highlight?

TS: I think specifically on pump technology there wasn't really anything particularly novel displayed. There were a range of pump companies, a new pump company I haven't seen before that was producing something based on the old Animas and Medtronic pumps. There wasn't really anything that most people haven't seen before, There were a number of symposium sessions where the likes on Insulet and Roche encouraged the discussion of their new products, but I think for the most part for me I had seen most of the pump technologies before and nothing made me go 'wow'. In that respect, the bit where it got interesting was the discussion around the integration of pump technology and algorithms and the different ways of doing that and the associated work that's been done in the US around separating those components and allowing them to be sold separately.

SH: You're right. In terms of any advances in pumps themselves beyond the something across the devices there probably wasn't a huge amount. I guess for me, thinking about themes that stuck out the big one was a talk that was related to skin reactions, which probably comes more under the CGM territory but equally for adhesives and how they cause skin reactions which is becoming a common theme I am seeing a lot more in the clinic population. I guess more so with CGM use and prolonged CGM use and this is also crossing into pump use and pump adhesives. It was an eye-opener about the importance of recognising that skin reactions to adhesives can occur anywhere in between $40 \%$ and $60 \%$ of people with type 1 diabetes at some point. In most cases, this might be a mild contact dermatitis, but in some cases can actually be an allergy which may sensitise them to other adhesives depending what is used. The other practical aspect was with relation to getting the best out of pump therapy that I guess is a nobrainer for those who have been doing pumps for a long time, but the more corrections you give, the more you are likely to get back in ranges and time in target. The other one was about the 7 days cannula options from Medtronic that was interesting and it will be interesting to see how that works as it would be interesting to see if it can give good absorption of insulin for that long period of time.

TS: Yes, I agree, I think there were three companies all talking about longer-term use of cannulas and we saw it from Medtronic, we saw it from Capillary Biomedical and we also saw it from Convatec. They have all either got a product that seems to be imminent or that is undergoing clinical trials right now in various places around the world. For me, the one that was most interesting to me was the Capillary Bio one that was also a sprinkler. For those that don't know what that means, it has multiple holes down the length of the cannula as well as at the bottom which is supposed to enable a more even release of insulin. In historical testing it has provided a quicker absorption of insulin. Speaking to them, they are more interested in maintaining a constant level of absorption over the life of the cannula and their cannula is made of a nylon rather than Teflon which is supposed to be more flexible and therefore act more effectively and cause much less inflammation at the site. The graphs from the testing so far suggest that we see half the level of inflammation we see from more traditional cannulas so all of these options present something very interesting for those of us that have been using cannulas, especially if they are less likely to cause damage which we are obviously hopeful means we can use pumps and cannulas for longer than perhaps we have been able to in the past mostly because the amount of site damage will be lower.

$\mathrm{SH}$ : Thanks for explaining that to me, Tim. That was actually good learning even for me. You have explained that so well. I have learnt a lot actually from our interactions so far and I am looking forward to the next half. Moving 
onto automated insulin delivery systems, which is obviously a very big theme in the technology world-encompassing both the regulated/unregulated options. Were there any big highlights on this for you, Tim?

TS: I think the biggest highlight was the amount of it there. The key for me in terms of automated insulin delivery was that we were discussing at the level of the providers commercially. We had discussions relating to the ethics around DIY and what guidelines need to be put in place for healthcare professionals and we had people discussing the ongoing academic space and looking at how they were doing the various things we have seen being done in the DIY spaces, as well as the review of what it's like to live with some of these systems and what needs to be taken into consideration from a psychological perspective. For me it was interesting to see the heaps of work that's been done to try and normalise the clinical trial outputs between control IQ and the Medtronic 670G; for those that weren't aware, the 670G did a before and after test with no control group, whereas the control IQ trial ran a control group with a central augmented pump against the control IQ algorithm so had a very clear baseline against which they were making a comparison. There has been a fair amount of discussion in the diabetes world as to the validity of the 670 trial given that the use of work that was done was to try and take those two slightly different approaches to the clinical trials and to say "how do we baseline both of these to a standard level to see what the real improvements were?" It was a really interesting piece of work and I think that it demonstrates that if we are going to see more clinical trials they must really conform to a standard set of approaches so that you don't have that kind of disparity. I hope that the commercial entities learn from that in the future in terms of what they actually offer. That was in itself an interesting session and in that same afternoon we also learned a bit more about the CamAPS FX product from Roman Hovorka and it was interesting to see his time in range data and also note the baseline HbA1c in his studies was $8.2 \%$ compared to a round about $7.5 \%$ in the other ones suggesting the people he put on his studies were significantly more similar to the average that we see in the UK if you look at our National Diabetes Audit data compared to those that the other companies have put in place. The fact that his 50 th percentile was $68 \%$ time in range given that was really quite incredible and would suggest that had his initial participants been more like those of the others he may well have produced better data. But anyway, that's all speculation just based on the statistical information that this presented. It does highlight to me that we have to be very careful comparing the different systems because the ways people present data, run their trials and create the reports that come out of all of this may not actually be easily 'read-acrossable' because the production is one that is very specifically targeted in a way that it is supposed to make a reader think about something. I think that was a highlight in the sense that it demonstrated the differences in approach but also was a bit if a thumbs down to the industry for not agreeing a protocol for this type of trial to make it easier for both patients and clinicians when they are trying to make a decision when looking at what the results are. That was a big point for me.

SH: That's very interesting. You're right that depending on the trial structure, patient selection and population and the demographics you select, how applicable will a set of results be? It was interesting that you mentioned Roman's group may have actually looked at people who are more representative of what I may see in my practice versus trials which have been probably more biased towards those who are more engaged or who have better self-management already in place and therefore they may see very different results in their entire system. So I think it is very hard to compare across trials and that is going to be a theme that we as clinicians must be very mindful of. Like you said, I think the one key message that came out was that there are a lot of automated insulin dosing systems out there and it is a very big theme and I suspect as the years evolve it will be something that we will have to approach as a common management option for type 1 diabetes, especially looking at a place like the United Kingdom where its uptake is at the moment fairly low. There are lots of options available; Tandem 
Control IQ, Diabeloop, the Cambridge system, the CamDiab CamAPS FX, Medtronic 670G that we have had for a few years but also Medtronic $780 \mathrm{G}$ which we had some mutterings about what it can offer as well. So there is a lot of variety coming in and with these systems as well there will be training that is required for healthcare professionals to utilise them and to understand how to use these systems and how to train people with diabetes how to use these systems and that can be something that will be important. Also, how do you select the right version for the right person? That comes back to things you mentioned, Tim, around the trials: what is more effective for the situation you are in, but also which device fits which person better? Which ecosystem of devices depends on whether its phone and CGM option might suit somebody more and there may be differences in the algorithm that could benefit some individuals more than another. This was just a regulated sector but obviously we've got the DIY aspects as well and that again to me was very much there at conference and we saw that in a number of sessions coming up at the forefront and it was good to see that as well, Tim.

TS: Yes I agree, I think one of the most reassuring things in any of the sessions was sitting and watching one of the Cambridge team discussing the things that they go through with their participants and trials related to use of AID [automated insulin dosing] systems and having the realisation that what they have been doing completely separately from us using the DIY systems was more or less exactly the same and that was a fascinating insight and was very pleasing that two completely separate routes arrived at the same set of understanding and the same set of messages being given to users that the way you do things relating to exercise and food and all these things is actually very similar across commercial and DIY systems so that people should be able to move between the two fairly easily if they choose to do so.

SH: Very true, Tim. I have often echoed to others that being part of a service that supports a lot of individuals who are on DIY systems, we have learnt a phenomenal amount that will help us immensely as it moves to regulated systems. I think the learnings we have gained as healthcare professionals who look after people with DIY systems will help us now that we will be using them with regulated versions as well and that's because, as you rightly say, the approaches and arriving at the same point is very similar across both sides. It is interesting to see that. Were there any other aspects, Tim, you wanted to discuss that we haven't touched on?

TS: I think another interesting aspect was wandering around the posters. There were some bits of information amongst those that perhaps weren't presented. The efficiency of the future algorithm around unannounced meals that we probably think is going to be the 780 algorithm had a poster looking at how that operated and how effective that was. There were also a whole bunch of posters provided by a variety of people looking at a bunch of things related to DIY systems. There was a poster looking at the way people used them out of Australia. There were people talking about how it had changed their life, and somebody taking quite an interesting psychological perspective on it, talking about homeliness and un-homeliness and how having a DIY APS system made them feel more home like again because as an adult being diagnosed you tend to get this kind of out of reality experience where you no longer feel like it's your own life anymore and having an APS and an AID system has helped them to feel more like they are living their own life again. Plus there were a variety of other topics that were covered on the DIY systems. So I think the most interesting poster in that respect for me was the one that looked at running the Android APS and the Loop on pigs, which for most people would seem to be a completely pointless exercise, but what I think it highlighted was how the two different systems deal with meals very differently and the algorithms have quite different ways of operating and as a result one seems to operate more effectively in respect of people not announcing meals compared to the other one. There was a lot of information in the posters that was really there and should have been looked at and I wonder how many people really did investigate some of those.

$\mathrm{SH}$ : I agree, there was a lot in the poster session that was very interesting. I am glad you mentioned that particular study from Stanford 
using DIY systems in pigs and the reasons behind it were obviously for providing more validity to the algorithms and it was excellent to see that come through. There was a poster you presented, Tim, wasn't there? Would you like to say more about it?

TS: Yes, I put together a poster that talked about citizen science and the role it has to play on the uptake of technologies and treatments in diabetes. The reason I put this together was because I write about a lot of stuff on Diabettech that looks at $n=1$ observations. As I do that I have the opportunity to look at what other people are doing. So whilst we have the 'we are not waiting' movement which has produced things like open APS loop and Android APS, plus the ability to share CGM information across the internet well before Dexcom had come up with the idea of doing that, we have also got individuals contributing to the diabetes technology world in a number of different ways and that includes the likes of me doing CGM comparison tests; but not just me, there have been multiple other people who have done similar things and as a body of work it should be quite interesting for people to find and read and understand. Things like the observational reaction to Fiasp that I did for around 9 months that allowed people to read about what was happening in the real world. Then you have the other section of people who have been assisting and using their skills to review publicly available data that may not be being linked up in an efficient way to present a story that can drive a campaign. The best example of that for me is what Nick Cahm has done in relation to Libre in the UK. I have talked about collection of data to which CCGs (Clinical Commissioning Groups) were not funding which were where the overarching rules were being changed to make it difficult to get the Libre on the NHS and as a result driving the Diabetes UK and JDRF [Juvenile Diabetes Research Foundation] campaign to make Libre available, which resulted in the NHS saying forget about the rationality, we're going to mandate this on an even wider level to make sure everybody gets equal treatment. I think those types of actions have also been something seen a lot in the diabetes community that also sometimes go unspoken. So the point in my poster was that there is a lot of $n=1$ reporting of things that go on in diabetes treatment and technologies. There are a lot of people interested in getting involved in looking at and crunching data and maybe even presenting a story slightly differently from people in the NHS because they have a different perspective. By painting these people into the clinical, regulatory and policy-making roles or at least gaining their assistance in those roles you can change the way technology is taken up. There is potentially something related to that which might fit into the education world as well although obviously that is something that needs to be taken a bit further.

SH: Brilliant, Tim. Thanks for explaining that in such detail. Anything else we haven't covered?

TS: I think the other area was the technology fair that was going on alongside the main exhibition where there were smaller companies talking about what they could do. We saw a number of companies who were looking at different ways to help MDI users with the advent of smart pens in relation to food and meal times. One of the interesting platforms we saw in the technology fair was "Snack" which offered a way of using the camera of your phone to take a photo of food and it will give you the macronutrient content, so, protein, fats and carbohydrates, but would also advise you on the portion size and whether it considers something as a small or large portion for you to then consider. Another app was called "Under My Fork" and what that tries to do is use photographs of food to allow you to catalogue meals but then to give you advice around the effects of the bolus you have given for that meal, the timing of that bolus and perhaps how you could perhaps adjust what you have done to reduce postprandial spikes either by giving more insulin or by adjusting your time. So we are starting to see those types of applications come about on smartphones which are doing something a bit different than traditional bolus advisers which in theory could enable easier management of glucose levels around meals, which for a long time has been one of the biggest struggles people have had living with type 1 diabetes. 
SH: I think it is a useful option for parts of the world where costs and health economics mean that pumps are hard to obtain and that might be a cost-effective way of trying to manage type 1 diabetes and using some form of algorithms and efficient support tools to help people with type 1 diabetes. Another was around nasal glucagon showing its efficacy; it is practically much easier to use than using injectable glucagon. We will wait and see how that story evolves. Beyond that there were lots of other interesting sessions along adjunctive treatments in type 1 diabetes, quite a lot about psychological aspects that we mentioned as well as education and other concepts around how we could look at CGM data that is FNIR (meaning fine, narrow and in range) and MGLR (more green left red) referring to the actual display colours in AGP (ambulatory glucose profile) traces and also percentage time in range metrics. These are also things that came out of my head. It has been really great talking to you, Tim. It has helped me learn more and I feel like I perhaps wasn't at the conference as much as I thought I was and I have learnt so much this evening, so thank you.

TS: Thank you, Sufyan. Yes, just on the point of fine, narrow in range you mentioned. That actually caused quite a bit of concern on social media because people saw the CGM trace and went 'wow!' that's really hard to achieve and there were questions about as to how people were achieving that type of trace whether it was legitimately someone living a busy, difficult life or whether it was someone with a regimented approach to what they did or someone who was very low cab and using a closed loop system. It certainly raised a lot of interest and questions and to some extent concern because people were concerned it would result in judgement of them for not getting that even though they were using a CGM system and that they might even be achieving let's say a $6.5 \%$ A1C, but because it wasn't so fine, narrow and in range getting a response from healthcare professionals that would not necessarily be all that comfortable.

$\mathrm{SH}$ : Very good point, Tim. In fact it is even true for the BGM [blood glucose monitoring] base target, the different diabetes population, the something time in range that was proposed in 2019 by the ADA [American Diabetes Association]. That is a similar sort of concern that was being put out as the target range of time in range between 3.9 and 10 [mmol/l] ideally being $20 \%$ or greater is actually phenomenally hard to achieve for the majority of people with type 1 diabetes. One of the concerns that when you use such measures as goal posts is that it can sometimes be used as a measure to try and reprimand someone or give a unrealistic target; both aren't great things to do. What I usually try and educate people on time in range aspects-I tell [them] that, well, this is an ideal scenario. The actual time in range goals for individuals need to be individualized for that particular person in that particular situation. So you're right, there is a danger that if we start using the measure fine, narrow and in range as an ideal that we should try and get to, it may not be achievable for most and a lot of people depending on the type of diabetes they have and type of life they live it will be very difficult and will cause even more distress it we put that as a benchmark to try and achieve. So I agree and thanks for that reminder, Tim.

VG: It was really interesting what you just said there that time in range has to really be individualised for each patient based on what they are going through and their lifestyle. There has been a huge emphasis put on the importance of time in range. Can I ask both of you, what is the important thing to you for time in range? Is it that you have to make sure your patients or that you yourself are sticking to that upwards of $70 \%$ time in range or is it more of a flexible goalpost that you can see as something to aim for?

SH: My thoughts as a healthcare professional are that these are not targets; they are goals that need to be individualised. What they are useful for in the clinical testing is to be used as a triage tool that allows you as a healthcare professional to figure out which part you need to focus on during your consultation. Time is short, so you have to cover a range of things; you are presented with a lot of data from CGM and it is very useful to use that as a snapshot. For example, if you see someone's time above range or time below range as areas that you need to 
focus more on, then those are areas you can try and drill down further. You still have to look at the detail and look at other metrics like mean and variability. That still is very important and most importantly you still have to remember the person and what they are going through. That is my main take-home message for healthcare professionals: they are not targets, they are goals that need to be individualised. You can use this to explain in consultations to add focus on areas during your consultation. For the person with diabetes or the carer, it's a reminder that it's not their target, its setting personal goals that is absolutely key. You need to always ask yourself if you're trying to obtain high standards: is this coming at a lot of mental burden or hypos or affecting other parts of your life? So those questions are equally as important for someone who even is getting very good results to ask themselves. My main messages to commissioners and funders are that can we also align our commissioning priorities with things like time in range because for me it is very hard if I see somebody who is collecting ok time below range just about but are not getting a very good target range and a very high time above range and that's because there is some fear around hypos, but don't I have the access to funding based on the current criteria to offer them a real-time continuous glucose monitor that has an alarmed alert so they can then take a bit more risk and improve without the fear of hypos. So how do we align our commissioning for the use of time in range and improving metrics that we would like to improve on with time in range? These are my take-home messages.

TS: I think time in range is an interesting one because I know a lot of people have put forward the concern that it results in yet another form of judgement. If you look at how people use time in range individually it varies an awful lot. The agreed consensus around the 3.9-10 millimole per litre provides a reference range within which people can operate, but it shouldn't be a target; it should be a recommendation or a goal that says if you're within this-great. The other thing that is important is to look at the data and to understand that if there is a lot that's under the $3.9[\mathrm{mmol} / \mathrm{l}]$ level or over the $10[\mathrm{mmol} / \mathrm{l}]$ level, understanding why that is happening. I think that comes back to the whole piece of work that has been done about diabetes distress and that plays into all of these things as well as fear of hypos and fear of long-term complications driving the behaviours that cause either of those things. So I think the time in range metric is a mechanism that can be used to help the diagnostic tool as much as anything else, but I think as well people should be encouraged to use it how they see fit and understand they can also set their own range of what they want to have as a target; it doesn't have to apply to the clinical consensus model either.

$\mathrm{SH}$ : That is a very good way of putting it, Tim. I think I have taken a few things away from that as well to probably try and use now. You're right that trying to look at it for recommendations for each individual, thinking where do you want to be and what next steps can I take and what is realistic for myself or the one I look after to achieve.

VG: Thank you both. I only have one last question for you both, so thank you for your time on our podcast today. I would like to ask both of you, what is the most important thing to you as type 1 diabetics when it comes to technology in diabetes? What is the thing you are most hoping will develop in technology and what do you think is going to be the most significant change we will see in the next 12 months?

TS: I think that in terms of technology, seeing the growth in the number of available AID systems is going to be important. Things we haven't talked about that was talked about at ATTD was things like stem cell or beta-cell implantation in encapsulated form and something that didn't really come up at ATTD at all was the smart insulin that I understand Novo are pretty close to getting into some sort of human trial. Whether these appear in the next 12 months I am not so sure but seeing progress in those types of technologies, that aren't necessarily AID systems or longer-term cannulas or longer lasting CGMs, will encourage people that there are alternatives available that fit in with the lifestyle they want to live rather than having to connect themselves up to come kind of technological device. I think that will play a key 
part in encouraging people, as well as the plethora of forthcoming technological devices, many of which are going to be very similar to one another.

$\mathrm{SH}$ : Interesting point. I guess for me, technologies need to be effective and need to be safe and easy to use but the one fundamental aspect that I would like to see change or improved on is cost. I say this not with my managers hat on but more with my global hat on. I grew up in a third-world country, so seeing the disparities in access to healthcare and having lived through very disparate examples of access to simple things it's quite important that we don't neglect how we can make some of these advances available to the vast majority of people living around the globe and not just restricted to those who are either in a health system that allows them to benefit from it or are economically in a position to afford it. I think the cost of systems in the future for me is going to be a very important theme that will allow people to benefit around the world. That's why when you're looking at lots of examples we have discussed which may be cheaper and apps and smart pens coming onto the scene it may allow us to look at other ways we can offer improvements at different costs to the wider healthcare systems around the globe.

TS: In terms of cost I think that it is fundamentally the biggest blocker to people having access to pretty much all tools out there and when you consider that the original patent for insulin was sold for a dollar because it wasn't considered that anyone should profit out of it. The idea that technology has burgeoned into such an industry and the cost involved in that industry to some people is quite phenomenally unpleasant and that level of access that is so hard for some people to have purely because of the cost of access to treatment really does need to be resolved.

VG: Thank you both so much. We have had a really excellent overview not only of the ATTD conference but of diabetes in general and where we are within type 1 diabetes at present. Thank you both so much for your time it has been a really interesting podcast and fantastic to speak to you both. You can listen to more podcasts by subscribing to Adis Rapid+ podcast with your preferred podcast provider, or by visiting the website. A full list of declarations, including funding and author disclosure statements, can also be found on the website.

\section{ACKNOWLEDGEMENTS}

Funding. No funding or sponsorship was received for this study or publication of this article.

Authorship. All named authors meet the International Committee of Medical Journal Editors (ICMJE) criteria for authorship for this article, take responsibility for the integrity of the work as a whole, and have given their approval for this version to be published.

Disclosures. Sufyan Hussain has received non-promotional educational speaker and/or advisory services for Medtronic, Roche, Dexcom, Abbott and Novo Nordisk. Tim Street discloses the following: served as a reviewer on the UK T1 Resources website, guest blog for DiabetesMine plus expenses covered to speak at DData 2019, sampler/Carb Tester for the Natural Low Carb Store, co-organiser of "Rise of the Machine" events, expenses covered to speak at EASD Postgraduate Course on Diabetes and Technology 2018, expenses covered by Diabetes UK Cymru to speak at their "Type 1 and Tech" conferences $2018 \& 2019$, expenses covered by Cambridge University for attending a focus group on their artificial pancreas, sponsored by Abbott Diabetes Care to attend DX 2019 in Lisbon on June 21st 2019 and paid speaker for ABCD meeting in 2019.

Compliance with Ethics Guidelines. This article does not contain any studies with human participants or animals performed by any of the authors.

Peer Review. Please note, contrary to the journal's standard single-blind peer review process, as an editorial this article underwent review by the journal's Editor-in-Chief. 
Data Availability. Data sharing is not applicable to this article as no datasets were generated or analyzed during the current study.

Open Access. This article is licensed under a Creative Commons Attribution-NonCommercial 4.0 International License, which permits any non-commercial use, sharing, adaptation, distribution and reproduction in any medium or format, as long as you give appropriate credit to the original author(s) and the source, provide a link to the Creative Commons licence, and indicate if changes were made. The images or other third party material in this article are included in the article's Creative Commons licence, unless indicated otherwise in a credit line to the material. If material is not included in the article's Creative Commons licence and your intended use is not permitted by statutory regulation or exceeds the permitted use, you will need to obtain permission directly from the copyright holder. To view a copy of this licence, visit http://creativecommons.org/licenses/by-nc/ $4.0 /$. 